\title{
Sustainable learning design in large transformational teaching and learning initiatives
}

\author{
Courtney Shalavin and Elaine Huber \\ University of Sydney Business School
}

\begin{abstract}
Ensuring lasting impact of transformational teaching and learning initiatives in higher education can prove challenging. The sustainability of such initiatives may hinge on capacity building of teachers, balancing innovation and sustainability during the design process and ensuring that the story of change is shared beyond those involved in the initial transformation. Using a case study example, this concise paper discusses how a transformational teaching and learning initiative in a large Australian Business School is approaching sustainable learning design through co-design, capacity building and the dissemination of research.
\end{abstract}

Keywords: learning design, sustainability, higher education, transformation, business education

\section{Introduction}

Innovation is closely linked to an individual teacher's appetite for change (Yurkofsky et al., 2020). When a teacher develops a new or revised unit through incorporating educational technologies or experimenting with delivery approaches, they usually see the developments through two or more cycles (or semesters) learning and improving as they go. They may work on these improvements over a significant time period in collaboration with other colleagues such as tutors, learning designers and educational developers in a 'networked teaching' approach (Mantai \& Huber, 2021). What then happens when the unit is 'handed over' to a new coordinator or teacher? This new teacher may not be as comfortable with the technologies or approaches used. The new teacher may regress the unit, removing any changes in favour of teaching approaches they are more familiar with. Afterall, they were not the change agents supported by a network of colleagues. They are merely the one that must carry that change onwards. How might we bridge this gap? In other words, how do we make sure our learning designs are both transferable and sustainable?

There are a number of ways we can consider the sustainability of learning designs. First, we need to engage in capacity building with staff towards new approaches to teaching. Learning design typically involves the implementation of new pedagogies supported by educational technologies. There is a plethora of professional development programs centred on higher education pedagogies from internal short courses to MOOCs and formal certifications. However, developing staff capabilities in educational technologies and digital literacies is often overlooked by universities (Huber \& Shalavin, 2018). Some have proposed a commitment to lifelong learning to support the longevity of design as it affects the professional identity of a teacher as a developer and innovator of learning (Kukulsa-Hulme, 2012). Others suggest a faculty-based Community of Inquiry (COI) that focuses on the development of learning innovations (Sharp \& Oliver, 2013; Wicks et al., 2015). And similarly, utilising bottom-up support and buy-in (rather than a management-down approach), through the development of discipline-based 'champions' (Viberg et al., 2019). Another way to build capacity is to do so implicitly during the development lifecycle. For example, through the active engagement and contribution of all involved from the commencement of the design process using collaborative approaches such as educational design research (Mckenney \& Reeves, 2018) or design-based research (Reimann, 2011). However, while the idea of co-design through engaging in theoretical discussion, reflection, and developing and prototyping ideas is essential (Cober et al., 2015), we often do not know the person or team who will take over the leadership of a unit in the future.

As we build capacity, we also need to look towards developing a shared or common language through which teachers and designers can speak, evaluate and reflect about learning design beyond the initiative itself (Dohn, Hansen \& Goodyear, 2019). Documentation is critically important to ensure that new staff to a unit or program understand the history of design decisions that have been made (McAndrew \& Goodyear, 2013). Development of learning design patterns may generate enough guidance to support human intervention and variation in each reuse (McAndrew \& Goodyear, 2013). Design patterns can document design principles (often the outputs from 
our educational design research), describe the end result and explain design paradigms (or guidelines) for how to develop an intervention, all of which enable transferability between units.

Designing across programs rather than across individual units can also help to ensure longevity of learning designs. Goodyear (2020) suggests that learning designs can be "nested" in that one design activity may provide "the infrastructure for subsequent design, teaching and study practices" (p. 1056). Goodyear (2020) also emphasises the vital role that faculty and infrastructure support play in embedding innovation. This viewpoint is supported by Viberg et al. (2019) who propose that faculty-based pedagogical developers are needed to drive and sustain the uptake of pedagogical change.

\section{Background context}

The context for this study is a large Australian Business School - the University of Sydney Business School with approximately 16,000 students, 500 staff and around 280 units of study delivered each semester. Many of the School's units have upwards of 1500 enrolments. This study is a subset of a large centrally funded strategic initiative - Connected Learning at Scale $(\mathrm{CLaS})$ - which aims to address the critical student experience and pedagogical impacts arising from increasing student numbers in large core Business School units. Students have reported feeling disconnected from their university experience, citing loneliness, isolation, a lack of connection with instructors and depersonalization as barriers to their learning in large classes (Bryant, 2019). CLaS is a transformative teaching and learning initiative focused on implementing connected learning pedagogy across the largest units in the School to develop a student experience that delivers networked, engaged, curious and innovative learners.

Over the past two years, a development team consisting of educational developers, learning designers, media producers and evaluative researchers has been collaborating with teaching teams across 17 large postgraduate and undergraduate units. As the initiative has progressed it has become increasingly evident that the innovations that have been co-designed and implemented require differing levels of ongoing maintenance and support depending on a range of contextual factors. Balancing the ongoing needs of faculty beyond the life of the funded initiative is the topic of this paper. We will highlight some of the issues the development team have faced and overview some factors we have considered to ensure the sustainability of learning design using a case study of one unit.

\section{Approach}

CLaS uses a design-based research approach that combines elements of design thinking, co-design and action research. This is also known as educational design research (McKenney \& Reeves, 2018). The development process has five distinct stages as shown in Figure 1. Our approach occurs across three cycles (one per semester) and each stage can occur several times in one cycle. Participating units have taken different approaches to the development cycles depending on the unit coordinator(s) availability and appetite for change.

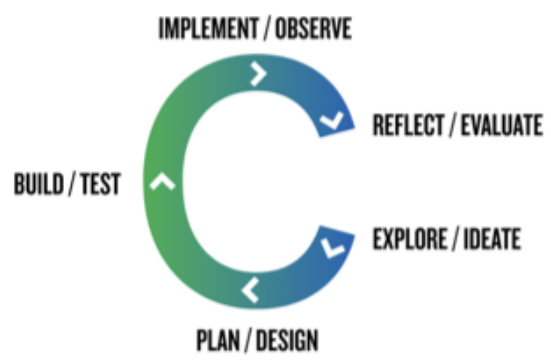

Figure 1. The five stages of the CLaS approach to design and development.

Evaluative data used during the co-design process is ethics approved. At present, evaluative data supporting this paper has been collected via student feedback surveys $(n=1159)$ and focus groups $(n=148)$; teaching team interviews $(n=23)$ and tutor focus groups $(n=43)$; learning analytics data from the learning management system and associated tools; observations of classroom spaces; and collection of artefacts from design workshops. 


\section{Case: A large postgraduate finance unit}

The following case study demonstrates how sustainable learning design was considered throughout the codesign process of a large postgraduate finance unit. The unit introduces foundational concepts in capital markets and corporate finance and prepares students for continued studies in the finance discipline. Student enrolment in the unit varies from 800 to 1400 students. The unit completed three cycles of iterative design and development as per the CLaS co-design process. The co-design team consisted of the core academic teaching team, an educational developer, a learning designer and an evaluative researcher. The following section will detail how sustainable learning design was considered throughout the unit's three development cycles.

\section{Cycle 1 and 2: Developing a shared language}

The first cycle of development focused on understanding the learning issues in the unit based on student feedback collected over the previous three semesters, in addition to self-reflections by the unit coordinator. Largely, these issues centred on large enrolment numbers which resulted in a lack of connection between students and the unit coordinator. Several small improvements were implemented as a result, including a course map to assist students with sensemaking of the unit content; short weekly podcasts in which the unit coordinator summarised key takeaways; use of a new tool to scaffold peer feedback on group contribution; and a live event during which the unit coordinator assisted students to prepare for the final exam and answered student's questions.

The second cycle of development entailed prototyping two weeks of blended learning consisting of two asynchronous online learning modules and two in-person workshops. The prototype targeted foundational mathbased learning content considered essential for success in the unit. Online modules consisted of screencast videos explaining key concepts coupled with interactive practice activities that provided automated feedback. In-person workshops provided students the opportunity to practice and extend their understanding of the content covered in the online modules.

Sustainability in the first and second cycle centred on building rapport with the unit coordinator and developing a shared language and approach to learning design (Dohn, Hansen \& Goodyear, 2019). In the first cycle, the unit coordinator was introduced to the co-design process and the team began co-designing processes for developing and implementing change in the unit. Tweaks to the unit were relatively small in scope and co-designed through a process of reflection and evaluation. It was in the second cycle that the shared language between the unit coordinator and development team began to blossom. The co-design team developed processes for production, with the unit coordinator participating in the design of the prototypes and supplying relevant copy and video scripts. The learning designer assigned to each initiative led the production of digital learning assets using copy supplied by the unit coordinator with the intent of handing over production to the unit coordinator in the third cycle.

\section{Cycle 3: Empowering through upskilling}

The third cycle of development was marked by the introduction of a new teaching team and the need to shift all learning content online in light of the coronavirus pandemic. Twelve modules of asynchronous online learning content were developed consisting primarily of screencast explainer videos, text-based learning content and practice activities. Unlike previous cycles, content development and production were driven primarily by the teaching team who recorded videos using the Business School's do-it-yourself recording studio and developed online learning content based on the prototypes implemented in the second development cycle. The development team shifted into a consultative role during this cycle and provided guidance and advice to the teaching team.

At the cessation of the third cycle the unit was handed over to the core teaching team and bespoke support was withdrawn. The teaching team received login details to educational technology accounts, one-on-one or group training on educational technologies and maintenance of their site in the learning management system (LMS) Canvas, and ongoing just-in-time learning design support for a period of one month. A central Canvas 'handover' page was used to document design decisions and collate asynchronous training materials for staff such as instructional videos, text-based instructional content explaining the purpose and use of educational technologies, and the basic hypertext markup language (HTML) needed to maintain the look and structure of the unit's Canvas site. 


\section{Discussion: Lessons to take forward}

A core component of sustainable learning design is upskilling academics in both pedagogy and educational technologies at the right time. In the case study above, the teaching team developed their capabilities in implementing innovative pedagogical approaches implicitly through the co-design process (Sharpe \& Oliver, 2013). However, the team did not participate in production of digital learning assets until the third cycle, and explicit upskilling activities focused on educational technologies occurred at the close of the project. Workshops and just-in-time support were provided during semester break, a period in which the teaching team were busy wrapping up marking, taking leave and catching up on research. As a result, the timing of the training may have decreased its saliency, as the team were unable to immediately apply what they had learnt. In future unit development projects, the development team intends to leverage the co-design process and encourage academic partners to engage in the production of learning assets from the first cycle onwards. This requires clear scoping and management of expectations from the beginning of the project lifecycle.

A major observation from the CLaS initiative is that change in ownership of a unit of study may break the chain of sustainability and negatively affect the continuity of innovation. In units that have a teaching team that spans semesters and years, knowledge of changes and understanding of the benefits that have come from change is retained and continues to grow (Cober et al., 2015). However, in units that are handed to a new coordinator who was not involved in the co-design process, we have observed overhauls and sometimes total removal of design elements and approaches developed during the co-design process. Not only do these changes result in negative morale for the co-design team, but they also raise questions about wasted resources and effort. In such instances, it becomes clear that the drivers for pedagogical change need to come from bottom up (teacher led) and top down (leadership guidelines) and that good communication and documentation is critical (Viberg et al., 2019). We have found that the role of project leader (or in our case educational developer) is critical to the ongoing sustainability of learning design as they act as a conduit to the discipline by keeping them abreast of challenges and improvements and, most importantly, of evaluation outcomes.

A planned output of the CLaS initiative is to develop a series of design patterns, as per the initiative's designbased research approach. Use of patterns offers a sustainable approach to learning design as they:

Describe[s] a problem which occurs over and over again in our environment, and then describe[s] the core of the solution to that problem, in such a way that you can use this solution a million times over, without ever doing it the same way twice (Alexander et al., 1977, p.x cited in Goodyear, 2005 p. 93)

Laurillard (2012) also discusses the idea of teaching patterns and the importance of providing the origin of the pattern or idea as well as the history of its development. This enables users of the pattern to make a valued judgement of its worth and at the same time credit the authors and developers of the pattern. The development of a pattern consists of context-problem-solution and, since our development work has spanned multiple units from across the 10 disciplines of the Business School, we are starting to see patterns emerging that can be shaped (via a template) and articulated to other educators who may be experiencing similar issues. At present, examples of emerging design patterns include reflection for learning; live question and answer sessions; distillation of core concepts; and student generated (authentic) data for learning. All of these patterns are underpinned by the factor of scale. However, noting further that the issues brought about by scale are often present independent of the discipline in focus and hence use of a pattern to create solutions is highly applicable.

\section{Conclusion}

The Connected Learning at Scale (CLaS) initiative is a strategic transformational learning and teaching initiative in the University of Sydney Business School. Iterative co-design cycles of ideation, design, development, implementation and evaluation have led to a greater understanding of the need for sustainable learning design to be incorporated as standard practice in order for innovation to be sustained. Identified are four main factors to support sustainable learning design in large transformational teaching and learning initiatives including upskilling of teaching staff in both educational technologies and pedagogical approaches; support of a networked teaching approach to ensure continuity of the design decision making process; communication across a discipline and program of the changes and benefits arising; and use of design patterns to promulgate evidence-based findings to common problems. We have demonstrated how some of these factors have been implemented in the CLaS initiative through a case study of one unit and discussed how we might move forward with future change and development initiatives. The initiative still has a number of years to run and work on the design patterns in collaboration with our academic partners will be critical to facilitate sustained-change at the School-wide level. 


\section{References}

Bryant, P. (2019). Finding their place in the world: Using digital storytelling to understand the intersections between students technology use and their work, life, play and learning. European Distance and E-Learning Network (EDEN) Conference Proceedings, 499-508. https://ses.library.usyd.edu.au/handle/2123/20695

Cober, R., Tan, E., Slotta, J., So, H.-J., \& Könings, K. D. (2015). Teachers as participatory designers: Two case studies with technology-enhanced learning environments. Instructional Science, 43(2), 203-228. https://doi.org/10.1007/s11251-014-9339-0

Dohn, N. B., Hansen, J. J., \& Goodyear, P. (2019). Basic design principles for learning designs to support knowledge transformation. In N. B. Dohn, S. B. Hansen, \& J. J. Hansen (Eds.), Designing for Situated Knowledge Transformation (pp. 160-179). Routledge. https://doi.org/10.4324/9780429275692

Goodyear, P. (2005). Educational design and networked learning: Patterns, pattern languages and design practice. Australasian Journal of Educational Technology, 21(1), 82-101. https://doi.org/10.14742/ajet.1344

Goodyear, P. (2020). Design and co-configuration for hybrid learning: Theorising the practices of learning space design. British Journal of Educational Technology, 51(4), 1045-1060. https://doi.org/10.1111/bjet.12925

Huber, E., \& Shalavin, C. (2018). Surveying the digital literacy landscape for academic and professional staff in higher education. In M. Campbell, J. Willems, C. Adachi, D. Blake, I. Doherty, S. Krishnan, S. MacFarlane, L. Ngo, M. O’Donnell, S. Palmer, L. Riddell, I. Story, H. Suri \& J. Tai (Eds.), $35^{\text {th }}$ International Conference of Innovation, Practice and Research in the Use of Educational Technologies in Tertiary Education (pp. 142-150). http://2018conference.ascilite.org/wp-content/uploads/2018/12/ASCILITE-2018-ProceedingsFinal.pdf

Kukulska-Hulme, A. (2012). How should the higher education workforce adapt to advancements in technology for teaching and learning? The Internet and Higher Education, 15(4), 247-254.

https://doi.org/10.1016/j.iheduc.2011.12.002

Laurillard, D. (2012). Teaching As a Design Science: Building Pedagogical Patterns for Learning and Technology. Taylor \& Francis Group.

McAndrew, P., \& Goodyear, P. (2013). Representing Practitioner Experiences through Learning Design and Patterns. In H. Beetham \& R. Sharpe (Eds.), Rethinking Pedagogy for a Digital Age: Designing for 21st Century Learning (pp. 341-367). Taylor \& Francis Group.

McKenney, S., \& Reeves, T. C. (2018). Conducting Educational Design Research (2nd ed.). Routledge. https://doi.org/10.4324/9781315105642

Mantai, L., \& Huber, E. (2021). Networked teaching: Overcoming the barriers to teaching experiential learning in large classes. Journal of Management Education, 45(5), 715-738. https://doi.org/10.1177/1052562920984506

Reimann, P. (2011). Design-Based Research. In L. Markauskaite, P. Freebody, \& J. Irwin (Eds.), Methodological Choice and Design: Scholarship, Policy and Practice in Social and Educational Research (pp. 37-50). Springer Netherlands. https://doi.org/10.1007/978-90-481-8933-5_3

Sharpe, R., \& Oliver, M. (2013). Designing for Learning in Course Teams. In H. Beetham \& R. Sharpe (Eds.), Rethinking Pedagogy for a Digital Age: Designing for 21st Century Learning (pp. 341-367). Taylor \& Francis Group.

Viberg, O., Bälter, O., Hedin, B., Riese, E., \& Mavroudi, A. (2019). Faculty pedagogical developers as enablers of technology enhanced learning. British Journal of Educational Technology, 50(5), 2637-2650. https://doi.org/10.1111/bjet.12710

Wicks, D. A., Craft, B. B., Mason, G. N., Gritter, K., \& Bolding, K. (2015). An investigation into the community of inquiry of blended classrooms by a Faculty Learning Community. The Internet and Higher Education, 25, 53-62. https://doi.org/10.1016/j.iheduc.2014.12.001

Yurkofsky, M. M., Peterson, A. J., Mehta, J. D., Horwitz-Willis, R., \& Frumin, K. M. (2020). Research on Continuous Improvement: Exploring the Complexities of Managing Educational Change. Review of Research in Education, 44(1), 403-433. https://doi.org/10.3102/0091732X20907363

Shalavin, C., \& Huber, E. (2021). Sustainable learning design in large transformational teaching and learning initiatives. In Gregory, S., Warburton, S., \& Schier, M. (Eds.), Back to the Future - ASCILITE '21.

Proceedings ASCILITE 2021 in Armidale (pp. 329-333). https://doi.org/10.14742/ascilite2021.0147

Note: All published papers are refereed, having undergone a double-blind peer-review process.

The author(s) assign a Creative Commons by attribution licence enabling others to distribute, remix, tweak, and build upon their work, even commercially, as long as credit is given to the author(s) for the original creation.

(C) Shalavin, C. \& Huber, E. 2021 